\title{
Os jovens "sem religião": ventos secularizantes, "espírito de época" e novos sincretismos. Notas preliminares
}

\author{
REGINA NOVAES
}

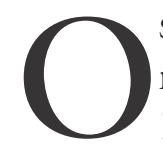

$S$ TRÊS PRINCIPAIS mudanças que caracterizam o campo religioso brasileiro hoje são, a saber: a diminuição percentual de católicos (de $83,76 \%$ em 1991 para $73,77 \%$ em 2000), o crescimento dos evangélicos (de 9,05\% em 1991 para $15,45 \%$ em 2000) e o aumento dos "sem religião" (de 4,8\% em 1991 para $7,4 \% \mathrm{em} \mathrm{2000)}$. Sobre os dois primeiros aspectos muito se tem escrito, sobre o terceiro bem menos.

De fato, ainda pouco se sabe sobre quem são os brasileiros "sem religião" que adentram o século XXI. Porém, algumas informações disponíveis permitem começar uma reflexão sobre o assunto. Este é o objetivo das presentes notas, nas quais focalizaremos, particularmente, os jovens brasileiros de quinze a 24 anos.

\section{Por onde sopram os ventos secularizantes?}

Relacionando religião e transferência intergeracional no Rio de Janeiro, o demógrafo René Decol (2001) afirmou que o fluxo atitudinal de católicos para outros grupos ganhou proporções de "mudança social” na medida em que está alterando significativamente e de forma definitiva o perfil religioso da população. Segundo o autor, o processo tem um componente demográfico: à medida que os grupos populacionais (coortes) se sucedem no tempo, menos adultos em idade de reprodução se declaram católicos, resultando em número cada vez menor de crianças recebendo influência desta natureza. A tendência é, portanto, um menor número de católicos no interior de cada coorte, fazendo com que a percentagem de católicos no conjunto da população decline de forma cada vez mais acentuada. Segundo o demógrafo, a estrutura social tradicional, onde valores e normas são transmitidos verticalmente, de geração em geração, passa a ser afetada cada vez mais por processos culturais, que atuam em planos horizontais, agindo sobre as coortes de forma diferenciada. Em sua análise, Decol (2001) enfatiza os ventos secularizantes que têm soprado pela sociedade.

O Censo de 2000 confirma tais observações. Para uma pergunta única e aberta - "qual é sua religião?" - em 2000, o IBGE recebeu 35 mil respostas diferentes, o que dá uma idéia da variedade com que o brasileiro define sua fé. $\mathrm{E}$ a tendência de diminuição dos que se declaram católicos se acentua entre os jovens, de quinze a 24 anos (que somam 73,6\%). Em relação a outras faixas 
etárias, segundo o Censo, o crescimento evangélico é um pouco menos acelerado entre os jovens (os jovens evangélicos somam 14,2\%, sendo 3,9\% de denominações tradicionais e $10,2 \%$ de denominações pentecostais). E, finalmente, é entre os que se declaram "sem religião" que os jovens $(9,3 \%)$ se destacam em relação ao conjunto da população $(7,4 \%)$.

Três anos depois do Censo, os resultados de uma pesquisa nacional realizada pelo Projeto Juventude/Instituto Cidadania ${ }^{1}$ confirmaram as mesmas tendências. Diferenciando-se do Censo, a pesquisa não indagou sobre religião através de uma pergunta aberta, a pergunta oferecia opções separadas como "agnós-ticos", "ateus" e quem "acredita em Deus mas não tem religião". Enquanto 65\% dos jovens entrevistados nesta pesquisa em todo o país se declaram católicos, $20 \%$ se declaram evangélicos (sendo $15 \%$ pentecostais e $5 \%$ não pentecostais) ${ }^{2}$. E foram $10 \%$ os jovens "sem religião", sendo que $9 \%$ declararam "acreditar em Deus mas não ter religião” enquanto apenas 1\% identificaram-se como ateus e agnósticos.

Através dos resultados da pesquisa Perfil da juventude brasileira podemos apresentar algumas características dos jovens que se definem como agnósticos e ateus. Eles somaram apenas 1\% (entre os quais 69\% são homens e 31\% são mulheres), no âmbito dos 3.500 entrevistados, entre os quais $41 \%$ se declararam brancos, $44 \%$ estão entre os que se declararam pretos ou pardos e 7\% dos que se declararam indígenas. Considerando o conjunto dos jovens entrevistados, em termos de renda familiar declarada, os ateus e agnósticos não estão entre os mais pobres, estão lado a lado com os espíritas kardecistas, seguidos por uma parcela de católicos, de evangélicos não pentecostais e de jovens das “outras religiões”. E estão, como era de se esperar, em termos de renda, mais distantes dos pentecostais que - junto com os adeptos das religiões afro-brasileiras - estão entre os mais pobres.

Os ateus e agnósticos, nesta mesma pesquisa, não estão predominantemente nem entre os jovens mais jovens (catorze a dezessete anos), nem entre os jovens mais velhos ( 21 a 24 anos); $50 \%$ deles estão na faixa etária intermediária (dezoito a vinte anos). O que pode indicar que este declarar-se "ateu" ou "agnóstico" pode fazer parte do momento da vida que é importante a afirmação de identidade independente em relação à família, como aconteceu com outras gerações. No entanto, chama atenção o fato dos entrevistados que se declararam ateus ou agnósticos viverem mais no interior do que nas regiões metropolitanas, contrariando um dos velhos cânones que relaciona ateísmo com os ventos secularizantes da urbanização modernizadora.

Vejamos agora os outros jovens entrevistados que declararam "acreditar em Deus mas não ter religião". Na pesquisa Perfil da juventude brasileira, eles somam $9 \%$ no conjunto dos entrevistados, sendo $64 \%$ de homens e $36 \%$ de mulheres, distribuem-se por todos os grupos de idade e estão um pouco mais entre os jovens mais velhos (21 a 24 anos). Em termos de educação formal, há uma aproximação entre os que "acreditam em Deus mas não têm religião" e os pentecostais, que se destacam pela pouca escolaridade. Em outras palavras, entre 
os jovens que ainda estão cursando o ensino fundamental ou que pararam de estudar nestas séries, somente os jovens evangélicos pentecostais entrevistados são em número um pouco maior do que os jovens que "acreditam em Deus, mas não têm religião". Já no ensino médio e na universidade, os que "acreditam em Deus, mas não têm religião" só são em maior número se comparados com os jovens adeptos da umbanda e do candomblé. Quanto à experiência de trabalho, os jovens que "acreditam em Deus mas não têm religião" são os que mais trabalham na cidade sem registro (45\%); ficam em quarto lugar entre os que trabalham na cidade com carteira assinada (19\%); são $17 \%$ entre os que fazem bicos na cidade; são $2 \%$ entre os que trabalham na agricultura familiar e outros $2 \%$ entre os que trabalham como assalariados no campo. Em resumo: seu perfil revela menos inclusão educacional e mais vulnerabilidades sociais.

Em termos de distribuição regional, na mesma pesquisa acima citada, temos os seguintes resultados: enquanto entre os jovens entrevistados o catolicismo predomina nas regiões Nordeste e Sul, os jovens evangélicos estão mais presentes no Norte/Centro-Oeste e no Sudeste. No Sudeste, também estão a maioria dos jovens espíritas kardecistas e os jovens adeptos das religiões afro-brasileiras que responderam o questionário da pesquisa. Quanto aos ateus e àqueles que “acreditam em Deus mas não têm religião" é interessante notar que mesmo havendo algum destaque para a região Sudeste, eles se distribuem por todas as regiões do país.

A disseminação desta opção "acredita em Deus, mas não tem religião" pode ser um elemento para explicar porque, em termos censitários, os "sem religião", que eram 0,2\% em 1940, cresceram 52\% na década de 1990. Porém, certamente, em 1940, os símbolos e significados presentes na resposta "sem religião" eram bastante diferentes dos dias de hoje.

Hoje e ontem há jovens que se definem como "ateus" e "agnósticos”, mas certamente em nenhuma outra época houve tantos jovens se definindo como "sem religião" que poderiam também ser classificados como "religiosos sem religião", isto é, adeptos de formas não institucionais de espiritualidade que são normalmente classificadas como esotéricas, nova era, holísticas, de ecologia profunda etc. Mas, ao mesmo tempo, também é significativo o número de jovens que se predispõe a mudar de religião e que reafirma seu pertencimento às igrejas evangélicas, às novas religiões japonesas, ao Budismo e, também, a grupos católicos ligados à Teologia da Libertação ou à Renovação Carismática.

\section{E quanto pesa o "espírito de época"?}

Mas, como diria Bourdieu, a estatística é apenas uma das formas de representar a vida social. O desafio da interpretação sociológica - mesmo quando a força da "evidência" dos números, das tabelas e gráficos parece marcante - é atribuir-lhes sentido que nunca perdem seu caráter hipotético. Ou seja, a explicação sociológica deve funcionar como "costura" produtora de inteligibilidade 
(Bourdieu, 1963, p. 10). Frente a esta nova configuração, a "costura" exige - pelo menos - três cuidados.

O primeiro cuidado diz respeito aos sentidos das palavras "ateu”, "agnóstico" e da expressão "não ter religião". Nada nos assegura que seus usos sejam os mesmos nem em termos de passado e presente, nem mesmo entre os jovens hoje entrevistados. Isto é, as autoclassificações dos jovens de hoje têm de ser pensadas em suas inter-relações no interior do campo religioso em transformação. Vejamos algumas respostas também retiradas da pesquisa Perfil da juventude brasileira que podem indicar diferentes apropriações destes termos.

Indagados sobre os valores que seriam mais importantes em uma sociedade ideal, a maioria ( $56 \%$ ) dos jovens que afirmaram "ter fé, mas não ter religião" se dispersou entre muitos valores propostos destacando "igualdade de oportunidades" (17\%). O "temor a Deus" (13\%) e a "religiosidade" (4\%) também foram incluídos em suas respostas. Vejamos agora as escolhas dos ateus e agnósticos. Estes concentraram-se sobretudo no "respeito ao meio ambiente" (48\%), mas quase $25 \%$ deles incorporaram a dimensão espiritual: $14 \%$ elegeram "temor a Deus", outros 14\% deles escolheram "religiosidade". Em resumo, os valores "temor a Deus" e "religiosidade" somaram 17\% das respostas daqueles que "acreditam em Deus, mas não têm religião" e $28 \%$ nas respostas dos ateus/agnósticos entrevistados.

Já não se fazem ateus como antigamente? E, por outro lado, relacionar as respostas daqueles que "acreditam em Deus, mas não têm religião" com a idéia corrente de que a ausência de fé favorece a possibilidade de crítica social? Afinal, são os jovens que "acreditam em Deus, mas não têm religião" que mais valorizaram a "igualdade de oportunidades", enquanto este aspecto foi muito pouco valorizado pelos ateus. Nesta mesma linha de questionamento, também chama a atenção a ênfase no "respeito ao meio ambiente" $(48 \%)^{3}$ entre os jovens que se declararam ateus. Lembrando o fato de que esta é uma geração que já recebeu como legado a "descoberta da ecologia", seria interessante saber o que significa este "respeito". Por um lado, é verdade que o "respeito ao meio ambiente" pode ser uma nova formulação para velhas e várias formas de valorização da natureza. Por exemplo, são conhecidas as relações rituais das religiões afro-brasileiras com a flora, o "respeito ao meio ambiente" pode ser a forma de reinterpretar e potencializar hoje práticas tradicionais. Mas, por outro lado, a ênfase ao respeito à natureza pode indicar também que "ser ateu" nos dias atuais pode não ser incongruente com a chamada "espiritualidade ecológica" e com novas possibilidades de (com)sagração da natureza.

Enfim, no que diz respeito particularmente à fé e às crenças, é preciso desnaturalizar pares de oposição consagrados que polarizam religião e participação política e/ou ciência e religião. Isto é, já hoje nos faltam evidências empíricas para aproximar automaticamente ausência de religião - ateísmo ou agnosticismo ao progresso da política e da ciência. 
O segundo cuidado diz respeito aos trânsitos já feitos e aos momentos de passagens entre religiões. De fato, as pesquisas são fotografias instantâneas da experiência dos jovens entrevistados, mas elas só permitem apreender percursos e processos nas trajetórias dos entrevistados quando se faz mais de uma pergunta sobre o tema religião. Tanto no Censo Demográfico quanto na pesquisa Perfil da juventude brasileira só havia uma pergunta sobre religião. Em outra pesquisa que desenvolvi no Rio de Janeiro, em 2001, intitulada Jovens do Rio ${ }^{4}$, fizemos outras perguntas sobre religião que permitiram identificar um contraditório tripé que se faz presente na experiência desta geração, a saber: a) forte disposição para mudança de religião; b) ênfase na escolha individual gerando maior disponibilidade para a reafirmação pessoal do pertencimento institucional; c) desenvolvimento de religiosidade sem vínculos institucionais.

Os "sem religião" poderiam, portanto, expressar a terceira possibilidade (item c). Porém, também a primeira possibilidade (item a) favorece a resposta "acredito em Deus, mas não tenho religião". Isto porque a disposição para mudar de religião cria vários momentos de interregno entre pertencimentos institucionais, isto é, momentos de busca entre os vários desenraizamentos que caracterizam o "espírito de época".

Na pesquisa Jovens do Rio, chamou a atenção o fato de mais da metade dos entrevistados - caracterizados como classe $\mathrm{C}$ - ter declarado já ter mudado de religião. Outro exemplo: na mesma pesquisa, no extrato mais pobre, ali caracterizado como classe $\mathrm{D}$, dois fenômenos se destacaram simultaneamente: quase um terço dos jovens se declararam "sem religião" e mais jovens se declararam evangélicos pentecostais do que católicos praticantes.

$\mathrm{O}$ terceiro cuidado diz respeito à necessidade de bem caracterizar as mudanças ocorridas na sociedade brasileira que tornam recorrente o pluralismo religioso intrafamiliar. Os resultados da pesquisa Jovens do Rio evidenciaram que o menor índice de transferência da religião dos pais para os filhos não desemboca necessariamente em secularização da sociedade, pois parte dos jovens que não seguem as religiões de seus pais católicos, buscam outras religiões. Os índices crescentes de evangélicos entre os jovens apontam para esta direção. Em outras palavras, se é evidente que o histórico catolicismo brasileiro perde com a diminuição da transferência intergeracional da religião, também não há garantia da total "transferência intergeracional" do ateísmo ou do agnosticismo. Na pesquisa Jovens do Rio, $50 \%$ dos entrevistados que declararam ter pais ateus ou agnósticos declararam ter eles próprios uma religião. A mesma pesquisa revelou ainda que frente à diminuição da influência da família na escolha religião, outras influências se revelam: para os entrevistados na pesquisa Jovens do Rio, a influência da família na escolha da religião pesou apenas para cerca de 50\% dos entrevistados, para o restante, a escolha da religião passava por outras justificativas, tais como, "motivos pessoais", "influência de amigos" e "influência de agentes religiosos". 
Em resumo, partilhando um certo espírito de época, os jovens desta geração estão sendo chamados a fazer suas escolhas em um campo religioso mais plural e competitivo. Os "sem religião" podem ser pensados como expressões locais de um global "espírito da época" no qual se expande o fenômeno de adesão simultânea a sistemas diversos de crenças, combinam-se práticas ocidentais e orientais, não apenas no nível religioso, mas também terapêutico e medicinal. Não podemos esquecer que, no mesmo Censo de 2000, o número de praticantes de religiões orientais cresceu, revelando mais budistas (245 mil) do que adeptos da religião judaica (101 mil). Os seguidores da doutrina do profeta Maomé (Islamismo) correspondem a 18,5 mil brasileiros. O Censo detalha também grupos que não apareciam nas estatísticas, como os praticantes de religiões esotéricas $(69,2$ mil $)$ e de tradições indígenas (10,7 mil).

Ou seja, estamos vivendo uma inédita conjugação entre "ventos secularizantes" e "espírito de época. Nos anos de 1980, o fim da guerra fria e a descrença na possibilidade de mudanças radicais já haviam produzido mudanças de formas e de conteúdo no caráter dos movimentos sociais contemporâneos. Os anos de 1990 evidenciaram crises de paradigmas que atingiram instituições religiosas e políticas. No que diz respeito ao campo religioso, velhos e novos fundamentalismos passaram a conviver com a emergência de um mundo religioso plural em que cresce a presença de grupos e indivíduos cuja adesão religiosa permite rearranjos provisórios entre crenças e ritos sem fidelidades institucionais.

Em um contexto de para "além das identidades institucionais", para os jovens de hoje se oferecem igrejas e grupos de várias tradições religiosas. Para eles também existem possibilidades de combinar elementos de diferentes espiritualidades em uma síntese "pessoal e intransferível" e assim se abrem novas possibilidades sincréticas.

\section{Velhos sincretismos e novas combinações?}

No momento atual, surge também a possibilidade de, entre os "sem religião", estarem jovens que se aproximam da umbanda, do candomblé ou do espiritismo.

Ao falar sobre as religiões mediúnicas, sempre se pergunta sobre seu futuro frente à escalada pentecostal. De fato, a olho nu, parecia ser maior o número de umbandistas e candomblecistas que, na última década, vinham assumindo publicamente suas identidades religiosas. Mas, apenas 1,4\% de espíritas kardecistas e $0,3 \%$ de umbandistas e candomblecistas aparecem no Censo de 2000. Embora a pesquisa Perfil da juventude brasileira tenha chegado a número maiores $(2 \% \mathrm{e}$ $1 \%$ respectivamente), a questão do futuro dessas tradições religiosas procede. Como explicar esses pequenos números quando se fala em maior diversidade religiosa no Brasil?

Em primeiro lugar, não há como negar que o crescimento pentecostal disputa "nas bases" com as religiões afro-brasileiras. Não é por acaso, diga-se de passagem, que a neopentecostal Igreja Universal do Reino de Deus elege entida- 
des e orixás como seus adversários mais poderosos. O exorcismo - ali denominado de libertação - pressupõe a crença no poder do inimigo.

Em segundo lugar, é preciso não esquecer que, certamente, muitos jovens entrevistados - como em gerações anteriores - continuam se definindo como católicos, sem deixar de ir a centros espíritas e a terreiros. Este fenômeno, bem conhecido entre nós, revela estratégias de apresentação social frente aos preconceitos e perseguições sofridas pelos adeptos das religiões afro-brasileiras ao longo da história, mas revela também sentimentos de "duplo pertencimento" que fazem com que um pai ou uma mãe de santo possam dizer, sem constrangimento: "sou católica e da umbanda" ou "sou católica e do santo".

E, em terceiro lugar - para além da onda evangélica - neste momento em que "ser católico" deixou de ser um requisito socialmente obrigatório, pode-se estar em vigor um novo expediente: freqüentadores dos centros espíritas, da umbanda e do candomblé podem estar engrossando as fileiras dos "sem religião". Esta hipótese está baseada em pesquisas que registram novas combinações entre crenças e práticas mediúnicas com outras vindas do chamado universo "nova era". Esta mistura pode ser observada tanto em lojas esotéricas que vendem produtos afro-brasileiros, como vice-e-versa.

Quanto aos espíritas kardecistas, deixando de ser socialmente induzidos a se incluir na maioria católica, eles não teriam o menor problema em definir-se como "sem religião". Afinal, como filhos do racionalismo francês, os espíritas sempre valorizaram o "caráter científico" da doutrina de Alan Kardec.

Enfim, de maneira geral, podemos dizer que as técnicas de comunicação e os avanços da tecnologia de ponta foram incorporados e contribuíram para a chamada globalização do campo religioso. Na televisão, nas lojas de produtos esotéricos, nas feiras, no rádio, já encontraram ofertas de "orientalização" das crenças ocidentais convivendo com uma difusa negação do dualismo cristão. No mundo globalizado, as crenças circulam, são apropriadas e reapropriadas. $\mathrm{Na}$ pesquisa Jovens do Rio buscamos apreender as crenças dos entrevistados de diferentes religiões, dos que "acreditam em Deus mas não têm religião" e também dos agnósticos e ateus. Entre os jovens entrevistados se fizeram presentes afrobrasileiros que crêem tanto em Orixás como no Espírito Santo, assim como jovens evangélicos pentecostais que afirmam acreditar em Orixás. Foram entrevistados católicos que afirmaram acreditar na reencarnação, mas também católicos e espíritas afirmaram suas crenças em orixás e energias esotéricas. E, o que mais interessa neste artigo, os jovens que se autoclassificaram como "sem religião" afirmaram acreditar praticamente em todos os itens do elenco oferecido: "energia”, astrologia, orixás, duendes e gnomos...

\section{Nota final}

Os jovens brasileiros, nascidos do final da década de 1970 para cá, já encontraram o mundo mudado. Eles fazem parte de uma geração pós-industrial, 
pós-guerra fria e pós-descoberta da ecologia. Vivem as tensões do avanço tecnológico, os mistérios do emprego, da violência urbana.

O que isto teria a ver com religião? Não me atrevo a afirmar que "o medo de sobrar", a insegurança para planejar o futuro profissional e a experiência de vivenciar precocemente a morte de amigos, primos e irmãos resultem, direta e necessariamente, em reforço de valores religiosos, busca de fé ou na valorização da religião como locus de agregação social. Apenas lembro que, para minorias militantes, as instituições religiosas continuam produzindo grupos e espaços para jovens onde são construídos lugares de agregação social, identidades e formam grupos que podem ser contabilizados na composição do cenário da sociedade civil. Fazendo parte destes grupos, motivados por valores e pertencimentos religiosos, jovens têm atuado no espaço público e têm fornecido quadros militantes para sindicatos, associações, movimentos e partidos políticos.

Mas, com o crescimento dos "sem religião", por que podemos dizer que para esta geração a fé está em alta? Os jovens de hoje já encontram questionada a histórica equação: "brasileiro"="católico". O declínio histórico do catolicismo no Brasil - relacionado com o crescimento evangélico e com o aumento daqueles que se declaram "sem religião" - produz mudanças fundamentais nas estratégias de apresentação social. É nesta geração que se generaliza a possibilidade de se declarar "sem religião", sem abrir mão da fé. "Ser religioso sem religião" significa, sobretudo, um certo consumo de bens religiosos sem as clássicas mediações institucionais como um estado provisório (entre adesões) ou como uma alternativa de vida e de expressão cultural.

Não por acaso, a Bíblia é o maior best seller do nosso tempo. Para ter acesso à Bíblia, os jovens brasileiros de hoje não precisam desconsiderar a autoridade dos padres ou pastores, nem precisam a eles se submeter. A Bíblia pode ser comprada em qualquer esquina e seus versículos são cantados nas letras de rap e aparecem escritos em outdoors no centro das cidades, nos muros das favelas e periferias. Expressando vínculos institucionais ou apenas crenças mais difusas, nos últimos anos, a linguagem religiosa se faz presente em muitas expressões juvenis na área de arte e cultura. Também não é por acaso que o Prêmio Hutus, considerado o mais importante do Hip Hop da América Latina, instituiu a categoria Hip Hop Gospel e também premia composições de "sem religião" que sem peias institucionais - falam de Cristo, de Oxalá e citam salmos bíblicos.

Neste contexto, a religião torna-se um fator de escolha em uma sociedade que enfatiza inúmeras possibilidades de escolhas, mas reduz acessos e oportunidades. Essas informações indicam a necessidade de novas abordagens e técnicas de pesquisa para compreender melhor no que consiste a singular (e internamente diferenciada) experiência religiosa desta geração. 
Notas

1 A metodologia, os critérios da amostra e os principais resultados desta pesquisa podem ser encontrados em www.projetojuventude.org.br

2 Na mesma pesquisa - Perfil da juventude brasileira - outros $1 \%$ dos jovens entrevistados indicaram igrejas classificadas como neocristãs, tais como Testemunhas de Jeová, Mórmons, Legião da Boa Vontade. Os espíritas e os jovens que se declaram adeptos das religiões afro-brasileiras somaram $3 \%$. Somam $1 \%$ os jovens que fizeram referência a outras minorias religiosas como judeus, islâmicos, budistas etc.

3 "Respeito ao meio ambiente" teve destaque também entre evangélicos históricos não pentecostais e adeptos da umbanda e do candomblé (35\%), e jovens de outras religiões $(21 \%)$.

4 Ver Novaes e Mello 2002.

Bibliografia

BOURDIEU, P. et alli. Travail et travailleurs em Algérie. Paris, La Haye, Mouton, 1963.

DECOL, René. "Imigração internacional e mudança religiosa no Brasil". Comunicação apresentada na Conferência Geral sobre População, Salvador, 2001.

NOVAES, Regina. "Religião e política: sincretismos entre alunos de Ciências Sociais". Em $A$ dança dos sincretismos. Rio de Janeiro, Comunicações do Iser, n. 45, ano 13, 1994.

. e MELLO, Cecília. Jovens do Rio. Rio de Janeiro, Comunicações do Iser, n. 57, ano 21, 2002.

PACE, Enzo. "Religião e globalização". Em ORO, A. P. e STEIL, C. A. (orgs.). Religião e Globalização. Petrópolis, Rio de Janeiro, Vozes, 1997.

TAVARES, M. F. e CAMURÇA, Marcelo. "Balanço dos estudos sobre juventude e religião". Universidade Federal de Juiz de Fora. Artigo inédito, 2004.

RESUMO - O NÚMERO de brasileiros "sem religião", sobretudo jovens de 15 a 24 anos, tem chamado a atenção dos estudiosos. O artigo aponta para a conjugação e a convivência entre: ideário secularizante (presente entre ateus e agnósticos); o "espírito do tempo" (presente entre aqueles que acreditam em Deus mas rejeitam instituições religiosas ou transitam entre pertencimentos institucionais) e, finalmente, as novas modalidades 
sincréticas (favorecidas pela perda de hegemonia do catolicismo e pela globalização do campo religioso).

ABSTRACT - THE NUMBER of Brazilians with "no religion", especially those between 15 and 24 years of age, has drawn the attention of scholars. This essay points to the conjugation and close association among: a secularizing creed (prevalent among atheists and agnostics), the "spirit of the age" (prevalent among those who believe in God but reject religious institutions or alternate between religious establishments), and finally, the new syncretic religious modes (impelled Catholicism's dwindling hegemony and the globalization of the religious realm).

Regina Novaesé antropóloga. Fez mestrado no Museu Nacional, UFRJ e doutorado na USP. É professora da Programa de pós-graduação em Sociologia e Antropologia do Instituto de Filosofia e Ciências Sociais, da UFRJ. É editora da Revista Religião e Sociedade. É autora de Os escolbidos de Deus (Marco Zero) e De corpo e Alma (Graphia). Tem vários artigos publicados sobre as relações entre religião e política, e, nos últimos anos, tem se dedicado ao estudo de expressões culturais juvenis.

Texto recebido e aceito para publicação em 18 de outubro de 2004. 